\title{
Radiotherapy Plus Total Androgen Block Versus Radiotherapy Plus LHRH Analog Monotherapy for Non-metastatic Prostate Cancer
}

\author{
GIULIA MARVASO $^{1}$, ANNA VIOLA ${ }^{2}$, CRISTIANA FODOR $^{1}$ and BARBARA A. JERECZEK-FOSSA ${ }^{1,2}$ \\ ${ }^{1}$ Division of Radiotherapy, European Institute of Oncology, Milan, Italy; \\ ${ }^{2}$ Department of Oncology and Hemato-oncology, University of Milan, Milan, Italy
}

\begin{abstract}
Background/Aim: Patients with locally advanced prostate cancer are generally treated with radiotherapy $(R T)$ which can be combined with hormonal therapy. RT plus monotherapy with luteinizing hormone-releasing hormone (LHRH) analog triptorelin was compared to RT plus total androgen block (TAB). Patients and Methods: A retrospective study was carried out on patients with locally advanced prostate cancer comparing RT plus monotherapy versus $R T$ plus TAB. Results: For overall survival, no differences between patients receiving $R T$ with monotherapy and those treated with $T A B$ were observed. A trend favoring use of TAB was found for progression-free survival. No differences in late gastrointestinal and genitourinary toxicities were reported. Conclusion: This study suggests that monotherapy with LHRH is as effective as $T A B$, which is important in selecting appropriate treatment considering that TAB can have higher risks of adverse events and reduce the quality of life of patients.
\end{abstract}

Prostate cancer is the second most frequent cancer in men preceded only by lung cancer (1). The outcome and treatment options for patients with prostate cancer mainly depend on the risk category to which they are allocated. The risk category is based on the classification of the National Comprehensive Centers Network, which stratifies non-metastatic prostate cancer into very low-, low-, intermediate-, high- and very high-risk categories according to the T stage, Prostate-specific antigen (PSA) level, and Gleason score (2).

For patients with locally advanced prostate cancer, radiotherapy (RT) is one of the main treatment options [as an alternative to surgery (3)], which can be combined with

Correspondence to: Giulia Marvaso MD, Division of Radiotherapy, Istituto Europeo di Oncologia, Via Giuseppe Ripamonti 435, 20141 Milan, Italy. E-mail: giulia.marvaso@ieo.it

Key Words: Prostate cancer, triptorelin, radiotherapy, therapy equivalence. androgen deprivation therapy (ADT) for patients with intermediate- and high-risk disease. The benefits of such addition of ADT have been reported in several randomized controlled clinical trials. Depending on the risk category of the patients, the benefit can differ (4). For low-intermediate risk patients, a large trial conducted on almost 2,000 individuals showed a clear advantage in terms of survival from the addition of ADT to RT (5). Subsequent post-hoc analysis indicated that the advantage in terms of survival was mainly found in patients with intermediate risk (5). Indeed, based on the recent large studies such as PROTECT (6), the first option for patients with low-risk prostate cancer has become active surveillance. If active therapy is proposed for these patients, only local therapy such as surgery or radiotherapy should be considered, with no indication for androgen deprivation. In patients with high-risk disease, ADT plus RT was found to significantly reduce the risk of local recurrence and confer a clear benefit in biochemical- and clinical progression-free survival (PFS) and a reduction in mortality, as shown in a pooled meta-analysis (7) of more than 4,300 patients.

One of the possible mechanisms for the increased efficacy of the combination RT and ADT over RT is through the reduction of DNA-repair capacity induced by ADT (8), which would increase cancer cell sensitivity to RT (i.e. inducing radiosensitization) together with a reduction of radioresistant hypoxic cells following $\operatorname{ADT}(9,10)$.

Hormonal therapy aims to induce a total androgen block (TAB), achieved by combining surgical or pharmacological castration with the use of luteinizing hormone-releasing hormone (LH-RH) agonist and antagonist, and direct androgen inhibitors, with steoridal anti-androgen drugs (SAA; such as ciproterone) and non-steroidal anti-androgen drugs (NSAA; among which the most used are flutamide and bicalutamide).

The present retrospective study aimed to compare LH-RH analog (triptorelin) as single agent and in combination with TAB (triptorelin plus NSAA or SAA) in terms of overall survival (OS) and PFS in patients receiving RT for prostate cancer. 


\section{Patients and Methods}

Patients. Fifty patients with prostate cancer diagnosed between 2002 and 2015 were considered in the present study. Of these, $36(72 \%)$ received RT plus TAB, while the remaining $14(28 \%)$ were treated with LHRH analog (triptorelin/decapeptyl) as monotherapy following RT.

All patients signed an informed consent form for the use of their anonymized data for research or educational purpose.

TAB was achieved by combining the LHRH analog (triptorelin/ decapetyl) with direct androgen blockers: bicalutamide or flutamide as NSAA, or with ciproterone as SAA.

Radiotherapy. Due to duration of this study, the patients were treated with different RT techniques and regimes but all were treated with a curative radiation dose.

The details of RT were published elsewhere (11-13). In brief, the patients were treated with three-dimensional conformal 2-dynamic arc RT, or since 2010, with intensity-modulated RT. Image guidance was introduced for daily target verification in 2006 and was based initially on ultrasound-based b-mode acquisition and targeting system (BAT; NOMOS, Cranberry Township, PA, USA) and then on stereo X-ray imaging system coupled with a 6 degree of freedom robotic couch (ExacTrac; BrainLAB, Feldkirchen, Germany) and cone-beam computed tomography.

An RT dose of $80 \mathrm{~Gy}$ in 40 fractions was employed until 2006; moderate hypofractionation was introduced thereafter based on the Fox Chase Cancer Center schedule (70.2 Gy given in 26 fractions of $2.7 \mathrm{~Gy}$ ), biologically equivalent to $84.24 \mathrm{~Gy}$ in $2.0 \mathrm{~Gy}$ fractions (linear quadratic model, $\alpha / \beta$ ratio of $1.5 \mathrm{~Gy}$ ) (14).

In 2012, extreme hypofractionation was introduced with the schedule of 35 Gy scheduled in 5 fractions on alternate days, namely $7 \mathrm{~Gy} /$ fraction, corresponding to a normalized total dose delivered at $2-\mathrm{Gy} /$ fraction (NTD2) of $85 \mathrm{~Gy}$, estimating an $\alpha / \beta$ ratio of $1.5 \mathrm{~Gy}$

Follow-up procedures. After the end of RT, clinical assessment and PSA measurements were performed every 3 months for at least 2 years and every 4-6 months thereafter. PFS was defined as the time elapsed from the end of external beam radiation therapy (EBRT) treatment to the time of clinical progression or disease specific mortality, and OS was defined as the time from commencing RT to the time of mortality from any cause.

The study was a part of curative RT research for patients with prostate cancer notified and approved by the Ethical Committee of the European Institute of Oncology, Milan, Italy (notification IEO N79-25th/October/2010).

Statistical analysis. A descriptive analysis in which clinical and demographic variables were compared in patients with receiving RT plus TAB or RT plus LH-HR analog was performed.

For categorical variables, the numbers and percentages have been reported, while for continuous variables, the median and interquartile range (IQR) values were considered. The $p$-values were calculated using $t$-test or the Wilcoxon test for continuous variables, while for categorical variables, the chi-square or Fisher exact test were used.

The OS and PFS curves, stratified for the different clinical variables, were obtained using the Kaplan-Meier method. The Kaplan-Meier method followed by a multivariate Cox model was used to simultaneously analyze the effect of all the variables on OS and PFS.

Stata software, version 11.2 (Stata Corp., College Station, TX, USA), was used for the statistical analysis.

\section{Results and Discussion}

The present retrospective study was conducted on patients with prostate cancer treated with RT and hormonal therapy. The main characteristics of the 50 patients are reported in Table I. Fourteen patients received LHRH analog as monotherapy (triptorelin). Thirty-six were treated with TAB using combination of triptorelin and anti-androgens; of these, 33 received NSAAs (26 bicalutamide and seven flutamide) and three received the SAA ciproterone.

The age of the patients and the Gleason score were similar for the two groups. The overall mean age at diagnosis was 70.5 years (72.3 years in the monotherapy group and 69.8 years in the TAB group) and the median Gleason score was 7 in both groups.

The tumor stage in the majority of the patients was T1, followed by $\mathrm{T} 2$ and $\mathrm{T} 3$. The number of patients with $\mathrm{T} 3$ diseases $(33 \%)$ was higher in the TAB group compared with the monotherapy group (7\%) but the difference was not statistically significant $(p=0.149)$. For the $\mathrm{N}$ stage, the majority of the patients had N0 disease $(>80 \%)$ with no statistically differences in the distribution between the two groups.

A statistically significant higher initial value of PSA was observed in the group receiving complete androgen block. The majority of the patients treated with monotherapy had an initial PSA level below $10 \mathrm{ng} / \mathrm{ml}$, while more than $70 \%$ of the patients treated with the TAB regimen had a PSA value greater than $10 \mathrm{ng} / \mathrm{ml}$, with $40 \%$ of them with a value higher than $20 \mathrm{ng} / \mathrm{ml}$.

The proportion of patients at intermediate-/high-risk was higher in the TAB group as compared to the monotherapy group (94.4 versus $86 \%$ ), although the difference was not significant $(p=0.269)$. No differences between the groups were found for concomitant pathologies.

Overall survival. The median follow-up was 65.7 months, ranging from 8 to 142 months. Twelve patients (24\%) died in this period of observation (Figure 1). Overall, survival rates of $81 \%$ and $60 \%$ were recorded at 5 and 10 years, respectively. No differences in terms of survival were observed when the two different treatment groups were considered. Non-statistically significant lower survival duration was observed for the TAB group compared to the monotherapy-treated patients (Figure 1).

The analysis conducted stratifying the patients according to the different clinical and demographic characteristics showed only non-statistically significant differences for age and T-stage. For age, better survival was found for patients aged less than 70 years compared with those with age greater than 70 years $(p=0.2464)$. For tumor stage, patients with T-stage $\geq 2$ had a greater overall survival than those with T-stage $<2(p=0.0688)$.

For all the other variables (initial PSA level, Gleason score, risk category, concomitant pathologies), no appreciable 
Table I. Main characteristics of the patients evaluated in this study.

\begin{tabular}{|c|c|c|c|c|}
\hline Characteristic & LHRH analog & TAB & Total & $p$-Value \\
\hline Number of patients (\%) & $14(28.0)$ & $36(72.0)$ & $50(100.0)$ & \\
\hline \multicolumn{5}{|l|}{ Age at diagnosis, years } \\
\hline Mean (SD) & $72.3(8.8)$ & $69.8(5.6)$ & $70.5(6.6)$ & 0.327 \\
\hline \multicolumn{5}{|l|}{ Age, N (\%) } \\
\hline$<65$ Years & $2(14.3)$ & $10(27.8)$ & $12(24.0)$ & \multirow[t]{4}{*}{0.118} \\
\hline 66-70 Years & $2(14.3)$ & $8(22.2)$ & $10(20.0)$ & \\
\hline 71-75 Years & $3(21.4)$ & $12(33.3)$ & $15(30.0)$ & \\
\hline$>75$ Years & $7(50.0)$ & $6(16.7)$ & $13(26.0)$ & \\
\hline \multicolumn{5}{|l|}{ T-Stage $(\%)$} \\
\hline $\mathrm{T} 1$ & $8(57.1)$ & $13(36.1)$ & $21(42.0)$ & \multirow[t]{3}{*}{0.149} \\
\hline $\mathrm{T} 2$ & $5(35.7)$ & $11(30.6)$ & $16(32.0)$ & \\
\hline $\mathrm{T} 3$ & $1(7.1)$ & $12(33.3)$ & $13(26.0)$ & \\
\hline \multicolumn{5}{|l|}{ N-Stage (\%) } \\
\hline No & $13(92.9)$ & $28(77.8)$ & $41(82.0)$ & \multirow[t]{3}{*}{0.369} \\
\hline N1 & $1(7.1)$ & $4(11.1)$ & $5(10.0)$ & \\
\hline $\mathrm{Nx}$ & 0 & $4(11.1)$ & $4(8.0)$ & \\
\hline \multicolumn{5}{|l|}{ Gleason score } \\
\hline Median (IQR) & $7(3)$ & $7(2)$ & $7(2)$ & 0.557 \\
\hline \multicolumn{5}{|l|}{ Gleason score, N (\%) } \\
\hline$<5$ & 0 & $1(2.8)$ & $1(2.0)$ & \multirow[t]{4}{*}{0.668} \\
\hline 6 & $4(28.6)$ & $10(27.8)$ & $14(28.0)$ & \\
\hline 7 & $4(28.6)$ & $15(41.6)$ & $19(38.0)$ & \\
\hline $8-10$ & $6(42.9)$ & $10(27.8)$ & $16(32.0)$ & \\
\hline \multicolumn{5}{|l|}{ Initial PSA, ng/ml } \\
\hline Median (IQR), & $9.1(7.1)$ & $14.5(20.9)$ & $12.7(15.0)$ & 0.077 \\
\hline \multicolumn{5}{|l|}{ Initial PSA, N (\%) } \\
\hline$<4 \mathrm{ng} / \mathrm{ml}$ & 0 & $2(5.6)$ & $2(4.0)$ & \multirow[t]{4}{*}{0.024} \\
\hline $4-10 \mathrm{ng} / \mathrm{ml}$ & $9(64.3)$ & $8(22.2)$ & $17(34)$ & \\
\hline $10-20 \mathrm{ng} / \mathrm{ml}$ & $4(28.6)$ & $12(33.3)$ & $16(32.0)$ & \\
\hline$>20 \mathrm{ng} / \mathrm{ml}$ & $1(7.1)$ & $14(38.9)$ & $15(30.0)$ & \\
\hline \multicolumn{5}{|l|}{ Risk category, N (\%) } \\
\hline Low & $2(14.3)$ & $2(5.6)$ & $2(4.0)$ & \multirow[t]{3}{*}{0.269} \\
\hline Intermediate & $6(42.9)$ & $10(27.8)$ & $16(32.0)$ & \\
\hline High & $6(42.9)$ & $24(66.6)$ & $30(60.0)$ & \\
\hline \multicolumn{5}{|c|}{ RT late toxicity $>\mathrm{G} 1, \mathrm{~N}(\%)$} \\
\hline GU & $2(14.3)$ & $11(30.6)$ & $13(26.0)$ & 0.303 \\
\hline GI & $6(42.9)$ & $16(44.4)$ & $22(44.0)$ & $>0.99$ \\
\hline \multicolumn{5}{|l|}{ Comorbidity, N (\%) } \\
\hline Overall & $10(71.4)$ & $30(83.3)$ & $40(80.0)$ & 0.436 \\
\hline Diabetes mellitus & $2(14.3)$ & $4(11.1)$ & $6(12.0)$ & 0.622 \\
\hline Cardiopathy & $5(35.7)$ & $15(41.6)$ & $20(40.0)$ & $>0.99$ \\
\hline Arterial hypertension & $6(42.9)$ & $18(50.0)$ & $24(48.0)$ & $>0.99$ \\
\hline Vascular pathologies & $5(35.7)$ & $8(22.2)$ & $13(26.0)$ & 0.241 \\
\hline Dyslipidemia & $1(7.1)$ & $7(19.5)$ & $8(16.0)$ & 0.653 \\
\hline
\end{tabular}

GI: Gastrointestinal; GU: genitourinary; IQR: interquartile range; RT: radiotherapy; SD: standard deviation.

differences in terms of survival were found. Interestingly, although RT is associated with both gastrointestinal (GI) and genitourinary $(\mathrm{GU})$ toxicities, the addition of TAB did not increase the rate of late RT complications, in agreement with the data reviewed by Ohri et al. (15).

In multivariate analysis, no statistically significant differences were found.
Progression-free survival. For PFS, the median follow-up was 68.6 months (range $=8-142$ months). Nine biochemical and macroscopic disease progression events were recorded, accounting for $24 \%$ of patients alive (Figure 2).

In univariate analysis, a statistically significant superior PFS was reported for the group receiving TAB compared to patients receiving monotherapy (Figure 2). For all the 

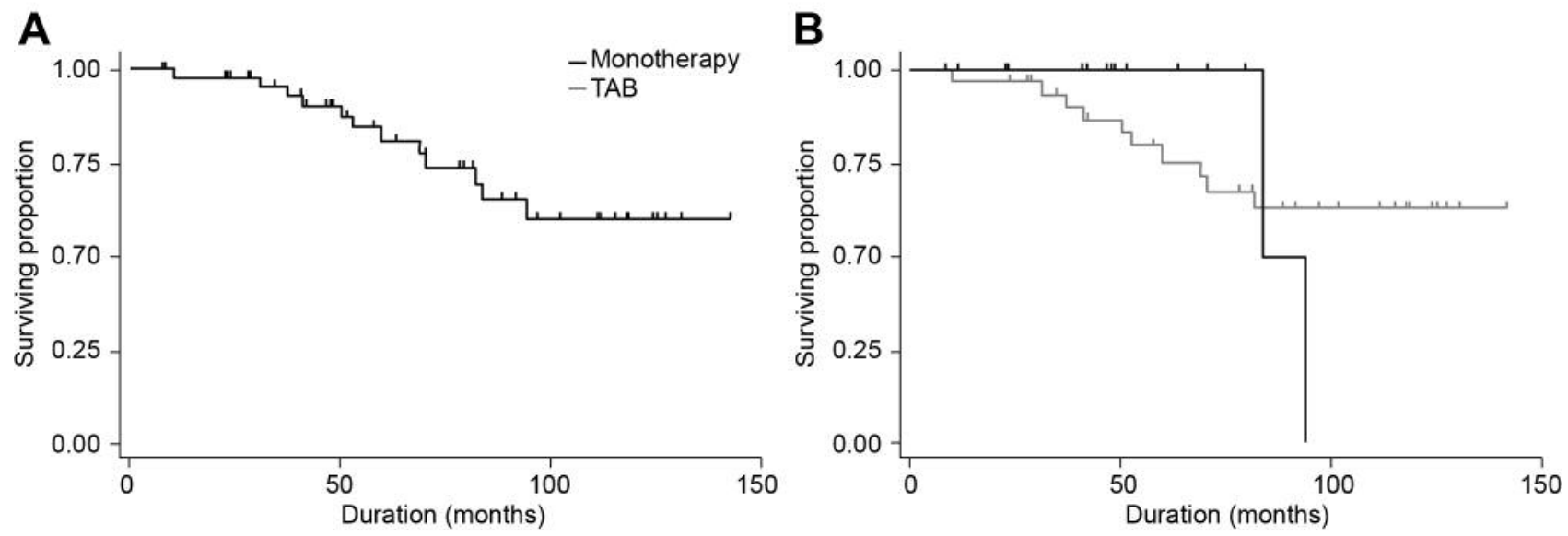

Figure 1. Overall survival of the total study population (A) and stratified for treatment (B). Mono: Monotherapy; TAB: total androgen block.
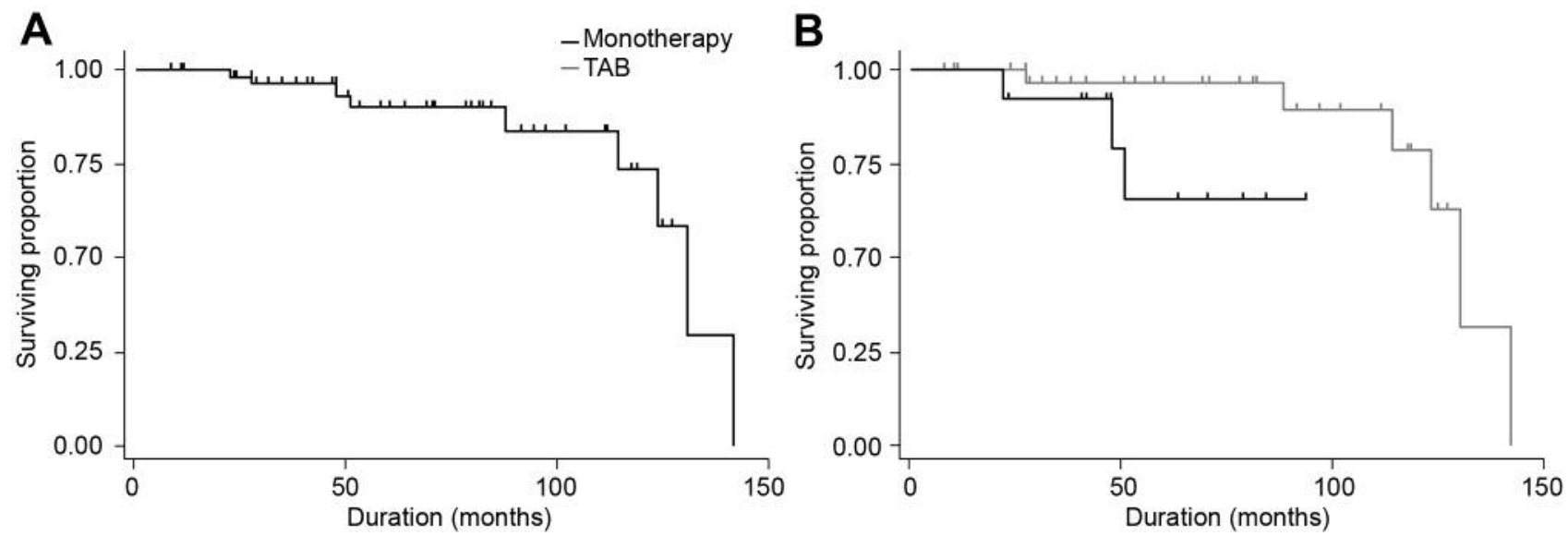

Figure 2. Progression-free survival of the total population (A) and stratified for treatment (B). Mono: Monotherapy; TAB: total androgen block.

other variables, no statistically significant differences were found. A higher PFS duration was found for younger patients $(p=0.1762)$, in patients with Gleason score $<7$ $(p=0.1540)$ and in patients with initial PSA $>10 \mathrm{ng} / \mathrm{ml}$ $(p=0.1295)$.

In multivariate analysis, a statistically significantly lower risk of relapse $(75 \%)$ was observed for patients receiving TAB; this difference, however, did not reach statistical significance $(p=0.277)$. Similarly, no differences were found for the other variables. While the data on PFS, when analyzed in univariate analysis, showed a significant benefit of TAB over monotherapy, on subsequent multivariate analysis (performed considering the main factors affecting the outcome) this lost statistical significance, although maintaining the same trend.
It is likely that the relatively small number of patients included in the present study, particularly those receiving LHRH as monotherapy, did not allow a proper (from a statistical point of view) and conclusive estimation of the benefit of monotherapy versus TAB. It seems, however, that monotherapy with triptorelin satisfactorily induced a good clinical benefit not different form that achieved by TAB.

Hormonal therapy is now indicated for patients with locally advanced prostate cancer at intermediate and, in particular, high risk $(5,7)$. A clear advantage has been demonstrated both in terms of reduced risk of relapse and in increased PFS $(5,7)$.

Altogether, the OS and PFS data seem to be in favor of a similarity between the effectiveness of the use of TAB and monotherapy. Considering that patients treated with 
monotherapy have advantages in terms of quality of life compared to those receiving TAB (16), the use of monotherapy could represent an interesting option, particularly for those patients more likely to be at risk of toxicity.

\section{Conflicts of Interest}

The Authors have no actual or potential conflicts of interest to declare in regard to this study.

\section{Acknowledgements}

Editorial support was provided by Content Ed Net, with helpful contribution in drafting the text by Giovanna Damia, and was funded by Ipsen SpA.

\section{References}

1 Siegel RL, Miller KD and Jemal A: Cancer statistics, 2017. CACancer J Clin 67: 7-30, 2017.

2 NCCN. National Comprehensive Cancer Network Clinical Practice Guidelines in Oncology (NCCN Guidelines ${ }^{\circledR}$ ). Prostate Cancer. 2016: Version 3, 2016. Available from: https://www.trikobe.org/nccn/guideline/urological/english/prostate.pdf.

3 Robinson D, Garmo H, Lissbrant IF, Widmark A, Pettersson A, Gunnlaugsson A, Adolfsson J, Bratt O, Nilsson P and Stattin P: Prostate cancer death after radiotherapy or radical prostatectomy: a nationwide population-based observational study. Eur Urol 73: 502-511, 2018.

4 Pagliarulo V, Bracarda S, Eisenberger MA, Mottet N, SchrÃ Jder $\mathrm{FH}$, Sternberg $\mathrm{CN}$ and Studer UE: Contemporary role of androgen deprivation therapy for prostate cancer. Eur Urol 61: $11-25,2012$

5 Jones CU, Hunt D, McGowan DG, Amin MB, Chetner MP, Bruner DW, Leibenhaut MH, Husain SM, Rotman M, Souhami L, Sandler HM and Shipley WU: Radiotherapy and short-term androgen deprivation for localized prostate cancer. New Engl J Med 365: 107-118, 2011.

6 Donovan JL, Hamdy FC, Lane JA, Mason M, Metcalfe C, Walsh E, Blazeby JM, Peters TJ, Holding P, Bonnington S, Lennon T, Bradshaw L, Cooper D, Herbert P, Howson J, Jones A, Lyons N, Salter E, Thompson P, Tidball S, Blaikie J, Gray C, Bollina P, Catto J, Doble A, Doherty A, Gillatt D, Kockelbergh R, Kynaston H, Paul A, Powell P, Prescott S, Rosario DJ, Rowe E, Davis M, Turner EL, Martin RM and Neal DE: Patient-reported outcomes after monitoring, surgery, or radiotherapy for prostate cancer. New Engl J Med 375: 1425-1437, 2016.

7 Bria E, Cuppone F, Giannarelli D, Milella M, Ruggeri EM, Sperduti I, Pinnarò P, Terzoli E, Cognetti F and Carlini P: Does hormone treatment added to radiotherapy improve outcome in locally advanced prostate cancer? Cancer 115: 3446-3456, 2009.
8 Polkinghorn WR, Parker JS, Lee MX, Kass EM, Spratt DE, Iaquinta PJ, Arora VK, Yen W-F, Cai L, Zheng D, Carver BS, Chen Y, Watson PA, Shah NP, Fujisawa S, Goglia AG, Gopalan A, Hieronymus H, Wongvipat J, Scardino PT, Zelefsky MJ, Jasin M, Chaudhuri J, Powell SN and Sawyers CL: Androgen receptor signaling regulates DNA repair in prostate cancers. Cancer Discov 3: 1245-1253, 2013.

9 Milosevic M, Chung P, Parker C, Bristow R, Toi A, Panzarella T, Warde P, Catton C, Menard C, Bayley A, Gospodarowicz M and Hill R: Androgen withdrawal in patients reduces prostate cancer hypoxia: implications for disease progression and radiation response. Cancer Res 67: 6022-6025, 2007.

10 Milosevic M, Warde P, Ménard C, Chung P, Toi A, Ishkanian A, McLean M, Pintilie M, Sykes J, Gospodarowicz M, Catton C, Hill RP and Bristow R: Tumor hypoxia predicts biochemical failure following radiotherapy for clinically localized prostate cancer. Clin Cancer Res 18: 2108-2114, 2012.

11 Garibaldi C, Jereczek-Fossa BA and Zerini D, Cambria R, Ferrari A, Serafini F, Cattani F, Tagaste B, Fodor C, Luraschi R and Orecchia R: Image-guided radiotherapy for prostate cancer using 3 different techniques: localization data of 186 patients. Tumori J 101: 273-280, 2015.

12 Jereczek-Fossa BA and Cattani F, Garibaldi C, Zerini D, Cambria R, Boboc GI, Valenti M, Kowalczyk A, Vavassori A, Ivaldi GB, Ciocca M, Matei DV, De Cobelli $O$ and Orecchia R: Transabdominal ultrasonography, computed tomography and electronic portal imaging for 3-dimensional conformal radiotherapy for prostate cancer. Strahlenther Onkol 183: 610-616, 2007.

13 Jereczek-Fossa BA and Vavassori A, Fodor C, Santoro L, Zerini D, Cattani F, Garibaldi C, Cambria R, Fodor A, Boboc GI, Vitolo V, Ivaldi GB, Musi G, de Cobelli O and Orecchia R: Dose escalation for prostate cancer using the three-dimensional conformal dynamic arc technique: analysis of 542 consecutive patients. Int J Radiat Oncol 71: 784-794, 2008.

14 Pollack A, Hanlon AL, Horwitz EM, Feigenberg SJ, Konski AA, Movsas B, Greenberg RE, Uzzo RG, Ma CMC, McNeeley SW, Buyyounouski MK and Price RA: Dosimetry and preliminary acute toxicity in the first 100 men treated for prostate cancer on a randomized hypofractionation dose escalation trial. Int J Radiat Oncol 64: 518-526, 2006.

15 Ohri N, Dicker AP and Showalter TN: Late toxicity rates following definitive radiotherapy for prostate cancer. Can J Urol 19: 6373-6380, 2012.

16 Samson DJ, Seidenfeld J, Schmitt B, Hasselblad V, Albertsen PC, Bennett CL, Wilt TJ and Aronson N: Systematic review and meta-analysis of monotherapy compared with combined androgen blockade for patients with advanced prostate carcinoma. Cancer 95: 361-376, 2002.

Received March 9, 2018 Revised March 29, 2018 Accepted April 2, 2018 